\section{Effects of Early Morning Physical Activity on Elementary School Students' Physical Fitness and Sociality}

\author{
Yongnam Parka , Jongho Moon ${ }^{\text {,** }}$
}

\author{
Received: 21 January 2018 \\ Revised: 05 March 2018 \\ Accepted: 13 March 2018 \\ ISSN: 1307-9298 \\ Copyright (C) IEJEE \\ www.iejee.com
}

DOI: 10.26822/iejee.2018438134

\begin{abstract}
As part of the Comprehensive School Physical Activity Program, we investigated how early morning physical activity affects elementary school students' physical fitness and sociality. Seventy-five boys in 6th grade of one elementary school located in G Metropolitan City, Korea comprised the experimental group that participated in early morning physical activity for 6 months. The control group did not perform said activities. Experimental design for this study adopted pre- and post-measurement and comparison methods between groups. Collected data were analyzed with analyses of covariance and Bonferroni post-hoc tests. The experimental group showed significant differences in the improvement of cardiorespiratory endurance and muscle strength among the sub-elements of physical fitness compared to controls. They also showed significant differences in the development of sociability, activity, autonomy, stability, and dominance among the sub-factors of sociality compared to controls. We elucidated the importance of early morning physical activity performed before school, which has implications for schools' physical education programs.
\end{abstract}

Keywords: Comprehensive school physical activity program, early morning physical activity, physical activity before school, physical fitness, sociality

\section{Introduction}

Physical activity in childhood is closely associated with health. Physical activity refers to all movement of the body caused by the contraction of the skeletal muscles (World Health Organization, 2015) and plays a vital role in energy consumption. However, despite many positive effects provided by physical activity, there is an increasingly decline in physical activity opportunities for students in school (Brusseau, Tudor-Locke, \& Kulinna, 2013). In addition, due to the characteristics of modern society and the way science and technology has increased individuals' sedentary lifestyle, opportunities for physical fitness have been reduced, which contributes to health problems such as obesity, chronic diseases (Mavrovouniotis, 2012). Recent research data shows that about one-third of adults are obese, which is associated with chronic diseases such as hypertension, diabetes, hyperlipidemia, and metabolic syndrome (i.e., "hypo-physical activity disease") (Flegal, Carroll, Ogden, \& Curtin, 2010; Kohl \& Cook, 2013). Since this phenomenon also occurs increasingly in younger age groups (Kann et al., 2015; NPAPA, 2016), it is necessary to recognize the importance of life-long physical activity and examine its effects during specific periods (Centers for Disease Control, 2011). Furthermore, 65-80\% of adolescents who are obese will be obese as adults (Guo, Chumlea, \& Roche, 2002; Wright, Parker, Lamont, \& Craft, 2001). In addition, adolescent obesity is associated with depression, low self-esteem, helplessness, isolation from peer groups, and mental and psychosocial problems (Baker, Beckstead, Mangelsdorf, \& Thummel, 2007). Therefore, additional physical activity opportunities are needed at school to improve the overall health and well-being of children (Dinkel, Lee, \& Schaffer, 2016).

To develop sociality, it is essential that sociality education is intentionally and deliberately performed, including socializing children from their families to community and school peer groups (Kim, 1996). Jang (2010) suggested that in addi- tion to improving students' physical fitness, physical activity can help social development to solve social problems such as the formation of good friendships and school maladjustment problems. Appropriate physical activity plays a positive role in developing sociality through sportsmanship, improved human relations, and stress relief. In addition, Lee \& Kim (2003) reported that students participating in physical play or sports activities are healthy, physically strong, socially adaptable, and can cope with stress. However, opportunities for participating in specifically planned and organized physical activity programs are few (Brusseau et al., 2013).

Efforts should be preceded to increase the physical activity time spent by elementary school students to solve these problems. Recently, the Comprehensive School Physical Activity Program (CSPAP) was presented internationally to address the lack of physical activity among children (Brusseau \& Hannon, 2015). The CSPAP includes five components: 1) quality physical education, 2) physical activity before and after school, 3) physical activity during school (both recess and classroom activity), 4) staff involvement, and 5) family and community engagement (CDC, 2013; NASPE, 2008). It is recommended that students get about 60 minutes of physical activity per day (U.S. Department of health and human services, 2008) since physical activity has a positive effect on students' knowledge, skills, and their confidence in being physically active throughout their lifetime (CDC, 2013).

Many countries recognize the importance of physical activity and are trying to solve health problems of children and adolescents through policies or projects using the CSPAP. The United States is reported to maintain health and prevent chronic illnesses in students through programs such as "Let's Move! Active Schools" program (CDC, 2015). They are placing a priority on physical education and physical activity in school education. In Europe, Ireland has implemented the "Active School Flag" program to form a school community with physically active habits. Finland has implemented the 
"Finnish Schools on the Move" program to promote students' physical activity. In addition, Germany employs a "Moving Schools" program to enhance its citizens' physical activity levels (Tannehil, van der Mars \& MacPhail, 2015). In sum, the CSPAP is being utilized internationally to ensure students' physical activity opportunities; however, many prior studies only focused on designing programs to simply increase students' participation time in physical activity rather than physical activity programs to achieve meaningful educational goals. In addition, there are many cases where programs for each country (Tannehill, Mars, \& MacPhil, 2015) and communities are not suitable to their own reality, resulting in application difficulties. This study, therefore, as a part of CSPAP, tried to make the goal clear that before school physical activity programs offer students an opportunity to be physically active and achieve meaningful educational goals.

Early morning physical activity was introduced through the success stories of Naperville high school students in IIlinois, USA, which indicated that physical activity programs conducted in school before formal classes were shown to activate the brains of the participating students and helped them improve their concentration and accomplishment (Ratey, 2008) Since the program was introduced, it has increasingly been conducted in schools across many countries; however, there are few detailed studies addressing the effects on the participating students other than those related to cognitive ability (Michael, Merlo, Basch, Wentzel, \& Wechsler, 2015). Moreover, most physical activity programs focus notably on the effects on students through formal physical activity during school.

Therefore, a study that addresses students' health, physical strength, schoolmate relationship, and school adaptability after participating in a regular and periodic early morning physical activity program is needed. Consequently, we examined elementary school students' physical fitness and sociality. It is anticipated that specifically examining the educational effects of students' participation in early morning physical activity will play a vital role in influencing school physical education programs to implement physical activity before school and ensuring that students get the required amount of physical activity each day.

\section{Method}

Early morning physical activity program

Early morning physical activity program was conducted about 40 minutes before the start of regular class. The students exercised on the school grounds or in the auditorium everyday for 6 months. To promote students' active participation in physical activity and keep them motivated continuously, we planned a program including exercises that they were usually interested in. As a result of asking students about their favorite physical activity, soccer was dominant. Therefore, to encourage the voluntary motivation of the students, we organized a program for soccer activities, and constructed another group for physical activities other than soccer. As a result, we separated students into 3 groups: (1) participated in soccer activities, (2) participated in other sport activities, and (3) a control group that did not participate in early morning physical activity (i.e., reading). Students participating in physical activities were encouraged to take part in the program by adjusting their intensity according to their own physical strength with maximum autonomy. In addition, we organized various forms of participation such as pair/group activities that allowed students to interact with their friends as well as individual activities (Table 1).
Table 1. Operating Program of Early Morning Physical Activities

\begin{tabular}{|c|c|c|c|}
\hline $\begin{array}{l}\text { Operating } \\
\text { program }\end{array}$ & $\begin{array}{l}\text { Activity } \\
\text { time }\end{array}$ & \multicolumn{2}{|c|}{ Activity details } \\
\hline $\begin{array}{l}\text { Warming } \\
\text { up }\end{array}$ & 5 min. & \multicolumn{2}{|c|}{$\begin{array}{l}\text { Preparatory gymnastics, } 2 \text { laps } \\
\text { around a 150-meter playground }\end{array}$} \\
\hline & & $\begin{array}{l}\text { Soccer } \\
\text { activities }\end{array}$ & $\begin{array}{l}\text { Other sport } \\
\text { activities }\end{array}$ \\
\hline $\begin{array}{l}\text { Main } \\
\text { exercises }\end{array}$ & $30 \mathrm{~min}$. & $\begin{array}{c}\text {-Basic skill } \\
\text { practices } \\
\text { (pass, kicking, } \\
\text { dribble, } \\
\text { shooting) } \\
\text {-Formal } \\
\text { soccer game }\end{array}$ & $\begin{array}{c}\text {-jumping rope, } \\
\text { table tennis, } \\
\text { dodge ball, } \\
\text { tee-ball, } \\
\text { badminton, } \\
\text { basketball, } \\
\text { soft-ball, } \\
\text { floor-ball }\end{array}$ \\
\hline $\begin{array}{l}\text { Cool-down } \\
\text { exercises }\end{array}$ & $5 \mathrm{~min}$. & \multicolumn{2}{|c|}{$\begin{array}{l}\text { Stretching or cool-down } \\
\text { gymnastics after running lightly }\end{array}$} \\
\hline
\end{tabular}

\section{Participants}

The participants selected for this study were 75 male students who were in the $6^{\text {th }}$ grade of elementary school, had not had a medical disease for 6 months, and had no difficulty exercising. We included only boys to control for developmental characteristics. The study purpose and design was explained in detail to parents in a school curriculum presentation session at the beginning of the semester. In addition, to control for differences in classroom culture and homeroom teachers, students were groups into the experimental or control group as a whole rather than by class. Participants' characteristics per group are shown in Tables 2.

Table 2. Participants' Physical Characteristics

\begin{tabular}{|c|c|c|c|c|}
\hline & & & $\begin{array}{l}\text { Height } \\
(\mathrm{cm})\end{array}$ & Weight (kg) \\
\hline \multirow{2}{*}{$\begin{array}{l}\text { Experimental } \\
\text { group A }\end{array}$} & \multirow[b]{2}{*}{$n(25)$} & Mean & 152.65 & 45.81 \\
\hline & & $\begin{array}{l}\text { Standard } \\
\text { deviation }\end{array}$ & 8.15 & 10.20 \\
\hline \multirow{2}{*}{$\begin{array}{l}\text { Experimental } \\
\text { group B }\end{array}$} & \multirow[b]{2}{*}{$n(25)$} & Mean & 151.15 & 44.42 \\
\hline & & $\begin{array}{l}\text { Standard } \\
\text { deviation }\end{array}$ & 5.37 & 7.51 \\
\hline \multirow[b]{2}{*}{ Control group } & \multirow[b]{2}{*}{$n(25)$} & Mean & 153.40 & 45.79 \\
\hline & & $\begin{array}{l}\text { Standard } \\
\text { deviation }\end{array}$ & 5.90 & 6.61 \\
\hline
\end{tabular}

Data collection

Physical fitness. To investigate the effect of participation in early morning physical activity, cardiorespiratory endurance, muscle strength, and flexibility were established as sub-elements of health fitness. Caspersen, Powell, \& Christenson (1985) defined the three components as measurable elements that reflect overall physical fitness. Also we have adopted example tests suggested by them as measurement of each three variables.

Cardiorespiratory endurance. We measured participants' ability to run as fast as possible using a 1000-m running or walking test. The running speed was recorded in seconds. The shorter the running time, the better participants' cardiorespiratory endurance.

Muscle strength. Participants were instructed to perform as many sit-ups as possible in 60 seconds. First they lied flat on their backs and bent their knees with putting their hands on their chest. And then repeatedly and as quickly as possible, they lifted their upper body in front of their 
Table 3. Mean and Standard Deviation of Pre-, Post-, Corrected-post-test Physical Fitness by Group

\begin{tabular}{|c|c|c|c|c|c|c|c|}
\hline \multirow[t]{2}{*}{ Sub-group } & \multirow[t]{2}{*}{ Group } & \multicolumn{2}{|c|}{ Pre-test } & \multicolumn{2}{|c|}{ Post-test } & \multicolumn{2}{|c|}{$\begin{array}{c}\text { Corrected } \\
\text { post-test }\end{array}$} \\
\hline & & $M$ & $S D$ & $M$ & $S D$ & $M$ & $S D$ \\
\hline \multirow{3}{*}{$\begin{array}{l}\text { Cardiorespiratory } \\
\text { endurance (seconds) }\end{array}$} & Experimental group A & 333.50 & 69.54 & 315.30 & 65.39 & 341.06 & 3.53 \\
\hline & Experimental group B & 352.73 & 42.47 & 316.07 & 31.66 & 327.38 & 3.91 \\
\hline & Control group & 403.95 & 49.30 & 404.10 & 48.93 & 369.86 & 3.66 \\
\hline \multirow{3}{*}{$\begin{array}{l}\text { Muscle Strength } \\
\text { (number) }\end{array}$} & Experimental group A & 34.20 & 12.92 & 43.20 & 14.32 & 37.05 & 1.23 \\
\hline & Experimental group B & 25.73 & 8.63 & 36.20 & 9.56 & 37.87 & 1.34 \\
\hline & Control group & 22.25 & 10.98 & 22.60 & 9.56 & 27.49 & 1.20 \\
\hline \multirow{3}{*}{ Flexibility (cm) } & Experimental group A & 5.37 & 6.61 & 8.75 & 6.25 & 8.02 & .75 \\
\hline & Experimental group B & 6.48 & 7.65 & 9.04 & 7.60 & 7.31 & .88 \\
\hline & Control group & 2.32 & 7.51 & 3.64 & 8.05 & 5.66 & .76 \\
\hline
\end{tabular}

knees and lied back again. It was measured by the number of times the sit-up posture was performed, and the higher the number of sit-ups, the better participants' muscle strength.

Flexibility. Participants were instructed to get their shoes off on a flat surface and sit straight on their knees. Allowing both feet to reach the measuring instrument vertically, they bent their upper body slowly and stretched their hands as far as possible using their waist and shoulders. The length they could reach was measured; the longer they could reach, the better participants' flexibility.

Sociality

Sociality Questionnaire. To measure sociality, we prepared a 30-item questionnaire by employing the assistance of 3 experts ( 1 professor and $2 \mathrm{PhD}$ in the major of physical education) and teachers in the same grade for the questionnaire, which Han (1998) prepared by amending and supplementing the personality test for elementary school developed by Jung (1971). The sociality sub-factors we measured were sociability ( 7 questions), activity ( 5 questions), autonomy (6 questions), stability (5 questions), and dominance (7 questions). Sociability means the degree of respecting others' opinions other than insisting on self-assertion, cooperating, exchanging with others, and interacting with them smoothly. Activity indicates the degree working hard and trying to accomplish tasks with enthusiasm. Autonomy implies being responsible for one's task plan, and practice. Stability means the degree of being emotionally stable and calmly coping in demanding situations. Lastly, dominance refers to one's assertion with others and persuading others to change their behaviors. Reliability of the Sociality Questionnaire: The validity of the sociality was verified by an expert that confirmed the accuracy, appropriateness of the contents, and terminology of the scale, and its reliability was measured using Cronbach's a. Cronbach's a is a reliability test that determines the measure's internal consistency, which is the degree of homogeneity between test questions. In this study, Cronbach's a values for the five sociality items ranged from .634 to .832 , indicating that the questionnaire was reliable. Each question was measured on a 5-point Likert scale, and higher scores indicate higher sociality.

\section{Data analysis}

The collected data were statistically analyzed using SPSS, and the statistical significance level was set to .05. To examine the effect of participation in early morning physical activity on physical fitness and sociality, we utilized means and standard deviations for pre and post-test scores.
Then, we compared the pure effects of such activity after eliminating the effects of pre-scores by group on postscores. Specifically, we performed analyses of covariance (ANCOVA) by setting all variables related to pre-scores as covariates and deriving and analyzing the corrected post-measured values. Next, a main effects analysis was conducted by employing Bonferroni post-hoc tests for sub-factors that had showed significant differences between the three groups.

\section{Results}

\section{Effects of early morning physical activity on physical fitness}

The respective mean and standard deviation of the pre-, post-, and corrected post-test or all three groups is shown in Table 3.

To compare the differences of sub-factors in physical fitness between the experimental groups $A$ and $B$ and the control group, we conducted an ANCOVA with corrected post-measured values after setting pre-scores as covariates for each group. And then Bonferroni's method was used for post-test to further investigate the differences between the three groups of corrected strengths that were statistically significant.

Effect on Cardiorespiratory Endurance. There was a statistically significant difference between groups in corrected cardiovascular endurance $(F=30.92, p<.05)$. According to the post-test, the mean difference between experimental group A and experimental group B was not statistically significant. The mean difference between experiment group $\mathrm{A}$ and control group was statistically significant ( $F=$ $-88.80, p<.05)$. In addition, the difference between the experimental group $B$ and the control group was statistically significant $(F=-88.03, p<.05)$.

Effect on Muscle Strength. There was a statistically significant difference between the groups in the corrected strength $(F=21.08, p<.001)$. According to the post-test, the mean difference between experimental group $A$ and experimental group B was not statistically significant. The mean difference between experimental group $A$ and control group was statistically significant $(F=9.57, p<.001)$. Also, the difference between the experimental group $\mathrm{B}$ and the control group was statistically significant ( $F=$ $10.39, p<.001)$.

Effect on flexibility. There was no statistically significant difference between the groups in the corrected flexibility ( $F=$ 2.48, $p>$.05). 
Table 4. Means and Standard Deviations of Pre-, Post-, Corrected Post-Sociality Test by Group

\begin{tabular}{|c|c|c|c|c|c|c|c|}
\hline \multirow[t]{2}{*}{ Sub-group } & \multirow[t]{2}{*}{ Group } & \multicolumn{2}{|c|}{ Pre-test } & \multicolumn{2}{|c|}{ Post-test } & \multicolumn{2}{|c|}{$\begin{array}{c}\text { Corrected } \\
\text { post-test }\end{array}$} \\
\hline & & $M$ & $S D$ & $M$ & $S D$ & $M$ & $S D$ \\
\hline \multirow{3}{*}{ Sociability } & Experimental group A & 4.29 & 3.33 & 4.46 & 3.57 & 4.54 & .93 \\
\hline & Experimental group B & 3.62 & 4.48 & 3.84 & 4.26 & 3.80 & 1.00 \\
\hline & Control group & 3.64 & 4.58 & 3.55 & 3.70 & 3.51 & .87 \\
\hline \multirow{3}{*}{ Activity } & Experimental group A & 3.72 & 2.80 & 4.07 & 2.32 & 4.09 & .60 \\
\hline & Experimental group B & 3.43 & 3.36 & 3.76 & 3.43 & 3.75 & .68 \\
\hline & Control group & 3.45 & 2.83 & 3.40 & 2.18 & 3.39 & .59 \\
\hline \multirow{3}{*}{ Autonomy } & Experimental group A & 3.76 & 3.12 & 4.01 & 4.29 & 4.06 & .87 \\
\hline & Experimental group B & 3.49 & 3.39 & 3.83 & 3.76 & 3.82 & .97 \\
\hline & Control group & 3.41 & 3.97 & 3.10 & 3.32 & 3.06 & .86 \\
\hline \multirow{3}{*}{ Stability } & Experimental group A & 3.51 & 3.03 & 19.50 & 4.44 & 19.44 & .89 \\
\hline & Experimental group B & 3.23 & 4.22 & 16.27 & 4.09 & 16.29 & 1.02 \\
\hline & Control group & 3.18 & 3.99 & 15.20 & 3.09 & 15.24 & .88 \\
\hline \multirow{3}{*}{ Dominance } & Experimental group A & 3.54 & 3.18 & 4.15 & 4.24 & 4.17 & 1.02 \\
\hline & Experimental group B & 3.45 & 4.58 & 3.69 & 4.99 & 3.68 & 1.18 \\
\hline & Control group & 3.37 & 5.62 & 3.14 & 4.92 & 3.12 & 1.02 \\
\hline
\end{tabular}

Effects of participation in early morning physical activity on students' sociality

The means and standard deviations for sociality in the pre-, post-, and corrected post-test between the three groups are shown in Table 4.

To compare the differences of sub-factors in sociality between experimental groups $A$ and $B$ and the control group, we conducted an ANCOVA with corrected post-measured values after setting pre-scores as covariates for each group. And Bonferroni's method was used for post-test to further investigate the differences between the three groups of corrected strengths that were statistically significant.

Effect on sociability. There was a statistically significant difference between the groups in the corrected sociability $(F=14.81, p<.001)$. As a result of post-test, the mean difference between experimental group $A$ and experimental group $B$ was statistically significant $(F=5.18, p<.01)$. The mean difference between the experimental group $A$ and the control group was statistically significant $(\mathrm{F}=7.17, p<$ .001). The difference between the experimental group $B$ and the control group was not statistically significant.

Effect on activity. There was a statistically significant difference between the groups in the corrected activities ( $F=$ $8.66, p<.01)$. As a result of post-test, the mean difference between experimental group A and control group was statistically significant $(F=3.51, p<.001)$. Also, the mean difference between experimental group $A$ and experimental group $B$, experimental group $B$ and control group was not significant.

Effects on autonomy. There was a statistically significant difference between the groups in the corrected autonomy $(F=12.63, p<.001)$. As a result of post-test, the mean difference between experimental group $A$ and experimental group $B$ was not statistically significant. The mean difference between experimental group $A$ and contro group was statistically significant $(F=6.00, p<.001)$. Also, the mean difference between experimental group $B$ and control group was statistically significant $(F=4.60, p<.01)$.
Effect on stability. There was a statistically significant difference between the groups in the corrected stability ( $F=$ $5.85, p<.01)$. As a result of post-test, the mean difference between experimental group $A$ and control group was statistically significant $(F=4.20, p<.01)$. The mean difference between experimental group $A$ and experimental group $B$, experimental group $B$ and control group was not statistically significant.

Effect on dominance. There was a statistically significant difference between the groups in the corrected dominance $(F=12.93, p<.001)$. As a result of post-test, the difference between the experimental group $A$ and the experimental group $B$ was not statistically significant. The mean difference between experimental group $A$ and control group was statistically significant $(F=7.38, p<.001)$. Also, the mean difference between experimental group $B$ and control group was statistically significant $(F=3.95, p<.05)$.

\section{Discussion and Conclusion}

Effects of participation in early morning physical activity on physical fitness

Early morning physical activity had a positive effect on the change in physical fitness of the $6^{\text {th }}$ grade male students who participated in this study. Experimental group $A$ and $B$ both improved significantly in overall physical fitness compared to the control group. Specifically, both experimental groups improved significantly in cardiorespiratory endurance and muscle strength excluding flexibility compared to the control group. The results are in agreement with Kim's (2012) study showing that the physical activity at the before class conducted for 12 weeks was effective in reducing the body fat percentage and increasing the muscle mass in middle school students, as well as demonstrating a positive effect on students' cardiorespiratory endurance. Further, Ha et al. (2013) reported that a exercise program conducted in the morning for 12 weeks with elementary school students induced positive effects on students' physical fitness and academic achievement, suggesting that early morning physical activity is positively associated with perceptive ability as well as physical fitness. Kim (2007) conducted rope-jump- 
ing exercises while listening to music in the morning for 16 weeks with elementary school students. Kim revealed that this program positively affected students' running ability, quick adaptation, and cardiorespiratory endurance. These results are partially consistent with our study.

Most of the early morning physical activity programs that students participated in for six months were activities directly related to the improvement of physical fitness. Participation in regular and autonomous physical activities had a positive effect on training students' healthy body and mind. Through participating in the program, students felt their physical strength improve, and they felt healthier. Particularly, the students who intensively participated in soccer showed significant differences in sub-factors of physical fitness, perhaps because soccer requires aerobic exercise and muscle strength. In addition, the group participating in various events showed increased interest confidence, and performance ability. We posit that both participating groups had improved overall physical fitness because of their daily, early morning physical activity. This should be implemented in schools' physical education programs to increase students' physical strength and decrease obesity. Effects of participation in early morning physical activity on
sociality

Early morning physical activity had a positive effect on the development of sociality in the participating students. Experimental group A and B improved significantly in sociality compared to the control group, including all five sub-factors (i.e., sociability, activity, autonomy, stability, dominance). Therefore, early morning physical activity is thought to have a positive effect on students' sociality and relationships with other students. These results are consistent with Lee and Kim (2013), who showed that soccer activities had various positive effects on participating students such as improvement of physical strength, stress relief, and formation of amicable social relations. Furthermore, they agree with the results of $\mathrm{Ha}$ (2002), who showed that participation in physical education activities by elementary school students was significantly related to independence, cooperation, and sociability as sub-factors of sociality. In addition, Cho (2001) revealed that participation in autonomous physical education activities had a positive effect on the development of accountability, stability, and dominance in higher-grade elementary school students. Lastly, the development of sociality such as sociability, independency, compliance, and cooperativeness in a group participating in regular sports activities was shown to be higher than the non-participating group (Choi, 2001), showing that sociability and cooperativeness among students who participate in group events develop better than among those who do not participate.

Students appeared to act friendly with their peers while participating in early morning physical activities. They were cooperative and had a sense of responsibility while performing several physical activities. In addition, there were students who, although usually liking exercises, passively participated in the program, or lacked confidence in certain school activities (e.g., the group participating in a variety of physical games and New Sports). However, steady participation in early morning physical activities was shown to lead such students to have time for communicating with their many friends, thus promoting peer relationships and improving adaptability to school life. Consequently, early morning physical activity had a positive effect on students' sense of affective stability and because it provides opportunities to not only cultivate joy in physical activity and cooperativeness (Ko, 2016), but also facili- tates interactions with peers naturally. In other words, autonomous and regular participation in physical activities is effective in the development of sociality by increasing students' school life satisfaction.

In sum, the importance of physical activity before school and in formal physical education classes has been clearly noted. We revealed the positive effects of elementary school students' participation in early morning physical activities, especially regarding physical fitness and sociality. In addition, it suggests that systematic physical activity programs should be organized and effective coaching or teaching and strategies are needed. Teachers not only provide opportunities for students to participate in simple activities like running, but to provide them with opportunities to participate in various and systematic programs in order to achieve more meaningful outcomes educationally. However, our study had some limitations. First, the experimental group participants were all boys from the sixth grade in $\mathrm{G}$ region, Korea. Subsequent research should be conducted with more diverse samples (i.e., sex, age, and geographic location). Second, it seems there exists differences in their physical fitness baseline between the groups, which raise a problem regarding random sampling. Although the pre-program score was set as covariate variable for each group so that we tried to verify only the effectiveness of participating in the program, that baseline of health fitness could work as a confounding variable. Third, it is necessary to study in detail what aspects of the program influence students' physical fitness and sociality. Future research should seek to determine, for example, the correlations between various elements such as regular physical activity, peer relationships, activities, teachers' instruction style, and students' attitudes.

\section{References}

Baker, K.D., Beckstead, R.B., Mangelsdorf, D.J., \& Thummel, C.S. (2007). Functional interactions between the moses corepressor and DHR78 nuclear receptor regulate growth in Drosophila. Genes and Development, 21(4), 450-464. doi: 10.1101/gad.1519007

Brusseau, T. A., \& Honnon, J. C. (2015). Impacting children's health and academic performance through comprehensive school physical activity programming. International Electronic Journal of Elementary Education, 7(3), 441-450. from: https://www.iejee.com/ index.php/IEJEE/article/view/90/88

Brusseau, T. A., Tudor-Locke, C., \& Kulinna, P. H. (2013). Are children meeting any of the suggested daily step recommendations?. Biomedical human kinetics, 5, 11-16. doi:10.2478/bhk-2013-0003

Caspersen, C.J., Powell, K.E., \& Christenson, G.M. (1985). Physical activity, exercise, and physical fitness: definitions and distinctions for health-related research. Public Health Rep. 100(2), 126-131.

CDC (2015). National framework for physical activity and physical education. Atlanta, GA: U.S. Department of Health and Human Services. Retrieved from https://www.cdc.gov/healthyschools/physicalactivity/pdf/National_Framework_Physical_Activity_ and_Physical_Education_Resources_Support_CSPAP_508_tagged.pdf.

Centers for Disease Control and Prevention. (2013). Com- 
prehensive school physical activity programs: A guide for schools. Atlanta, GA: U.S. Department of Health and Human Services. https://www.cdc.gov/healthyschools/professional_development/e-learning/ cspap/_assets/FullCourseContent-CSPAP.pdf

Centers for Disease Control and Prevention. (2011). School health guidelines to promote healthy eating and physical activity. MMWR, 60, 1-76. PMID: 21918496

Choi, C. S. (2001). The Relationships between participating in sport activities and sociability of elementary school students. (Master thesis, Korea national University of Education, Seoul, Korea)

Dinkel, D. M., Lee, J. M., \& Schaffer, C. (2016). Examining the knowledge and capacity of elementary teachers to implement classroom physical activity breaks. International Electronic Journal of Elementary Education, 9(1), 182-196. from: https://www.iejee.com/ index.php/IEJEE/article/view/151/148

Flegal, K. M., Carroll, M. D., Ogden, C. L., \& Curtin, L. R. (2010). Prevalence and trends in obesity among US adults, 1999-2008. JAMA, 303(3), 235-241, doi: 10.1001/jama.2009.2014

Guo, S. S., Wu, W, Chumlea, W. C., \& Roche, A. F. (2002). Predicting overweight and obesity in adulthood from body mass index values in childhood and adolescence. The American Journal of Clinical Nutrition. 78(3):653-658. PMID: 12198014

Ha, C. D., Hong, H. R., Cho J. H., Cheun, J. Y., \& Seo, Y. H. (2013). Effects of taebo exercise on physical fitness and academic performance in elementary school children. The Korean Journal of Growth and Development, 21(2),109-115.

Ha, J. Y. (2002). The influence of elementary school students physical activities on the development of sociability. (Master thesis, Kyung-sung University, Busan, Korea).

Han, T. R. (1998). The relationship between sport participation and social development in youth. (Master these, Seoul National University, Seoul, Korea).

Jang, Y. G. (2010). Justification of elementary physical education and the 2007 Revised Curriculum. The Journal of Korea elementary education, 21(2), 325-337.

Jung, B. M. (1971). A personality test manual: Senior grade in elementary school. Seoul: Korea Testing Center.

Kann, L., McManus, T., Harris, W. A, Shanklin, S. L., Flint, K. H., Hawkins, J., Queen. B., Lowry, R., Olsen, E. O. Chyen, D., Whittle, L., Thornton, J., Lim, C., Yamakawa, Y., Brener, N., \& Zaza, S. (2016). Youth Risk Behavior Surveillance-United States, 2015. MMWR 65(6), 1-174. doi: 10.15585/mmwr.ss6506a1.

Kim, M. H. (1996). The effects of role-playing teaching on leaner's social maturity. (Master thesis, Kon-kuk University, Seoul, Korea)

Kim, Y, K. (2007). The effect of morning music rope-skipping exercise on elementary school student's physical fitness. (Master thesis, Korea national Sport University, Seoul, Korea)

Kim, Y. Y. (2012). Influence of zero hour class physical activities on junior high school students physical fitness, physical self-efficacy, academic achievement and attitude toward learning. (Master thesis, Yongin University, Gyounggi-Do, Korea).

Kohl Ш, H. W., \& Cook, H. D. (2013). Educating the student body: taking physical activity and physical education to school. Washington D.C., National Academies Press(US).

Ko, W. H. (2016). Effect of early morning sport activity on enjoyment of physical activity and school life satisfaction of Elementary School Students. (Master thesis, Korea National University of Education, ChungBuk, Korea).

Lee, D. H. \& Kim, J. S. (2003). The teaching methods of character education through physical education. Journal of Korean Society for the Study of Physical Education, 7(4), 17-37.

Lee, G. I. \& Kim, K. O. (2013). Educational achievements and Challenges of Sports Club System for Every Morning: Focused on the D Middle School. Secondary Institute of Education, 61(4), 1033-1060.

Mavrovouniotis, F. (2012). Inactivity in Childhood and Adolescence: A Modern Lifestyle Associated with Adverse Health Consequences. Sport Science Review, 21(3-4), 75-99. doi: 10.2478/v10237-012-0011-9

Michael, S.L., Merlo, C.L., Basch, C.E., Wentzel, K.R., \& Wechsler, H. (2015). Critical connections: health and academics. Journal of School Health. 85(11):740-758. doi: 10.1111/josh.12309.

National Association for Sport and Physical Education. (2008). Comprehensive school physical activity programs. Reston, VA: NASPE.

National Physical Activity Plan Alliance. (2016). 2016 US report card on physical activity for children and youth. Columbia, SC: NPAPA.

Oh, H, K. (2001). The relationship between participation in intramural physical activity programs and the development of children's sociability. (Master thesis, Seoul National University of Education, Seoul, Korea).

Ratey, J. J. (2008). Spark-The revolutionary new science of exercise and the brain. New York: Little Brown and Company.

Tannehill, D., van der Mars, H., \& MacPhail, A. (2015). Building delivering and sustaining effective physical education programs. Sudbury, MA: Jones \& Bartlett.

U.S. Department of health and human services. (2008). Physical activity guidelines advisory committee report. Washington, D.C: U.S. Department of Health and Human Services

World Health Organization (2015). World health statistics. 
Geneva: WHO.

Wright, C. M., Parker, L., Lamont, D. \& Craft, A. W. (2001). Implications of childhood obesity for adult health: findings from thousand famillies cohort study, British Medical Journal, 323, 1280-8. doi: 10.1136/ bmj.323.7324.1280.yschools/professional_development/e-learning/cspap/_assets/FullCourseContent-CSPAP.pdf 